https://doi.org/10.25208/0042-4609-2018-94-4-60-67

$\mathrm{M}$

икробная экзема: возможности коррекции на современном этапе

Тлиш М. М., Кузнецова Т. Г. *, Наатыж Ж. Ю, Псавок Ф. А.

Кубанский государственный медицинский университет Министерства здравоохранения Российской Федерации 350000, Российская Федерация, г. Краснодар, ул. Рашпилевская, д. 179

Микробная экзема - хронический рецидивирующий дерматоз, характеризующийся эволюционным полиморфизмом элементов сыпи, мокнутием, зудом, аллергической реакцией сенсибилизированной кожи на продукты распада микроорганизмов и их токсины, развивающийся на фроне длительно существующего пиогенного очага при нарушении важнейших регуляторных систем организма.

Цель: изучить биоценоз кожи у больных микробной экземой и оценить клиническую эфрфективность и безопасность применения крема «Тетрадерм» у таких пациентов.

Материалы и методы. Под наблюдением находились пациенты с микробной экземой, методом случайного отбора разделенные на две группы. У всех больных изучен биоценоз кожи до и после лечения. Больные исследуемой группы получали топическую терапию кремом «Тетрадерм». Наружная терапия пациентам группы сравнения проводилась кремом мометазона фуроата в сочетании с эритромициновой и клотримазоловой мазями. Эфрфективность проводимой терапии оценивали с учетом клинической динамики кожного процесса, данных бактериологического исследования содержимого пустул и отделяемого эрозий, расчета индексов EASI и ДИКЖ.

Результаты. Сравнительный анализ биоценоза очагов микробной экземы у пациентов обеих групп к моменту окончания терапии показал более высокую выраженность дисбиотических изменений в группе сравнения. В результате проведенного нами исследования установлено, что у пациентов, применявших крем «Тетрадерм», отмечался более быстрый регресс дерматоза, практически полное подавление патогенной бактериальной фрлоры, значительное улучшение качества жизни.

Заключение. Биоценоз кожи больных микробной экземой характеризовался высокой степенью обсемененности Staphylococcus aureus и Staphylococcus epidermidis на фроне средних показателей верификации Streptococcus spp., Candida spp. Комбинация выраженного противовоспалительного, антибактериального, антимикотического и регенерирующего эфрфектов крема «Тетрадерм» обусловливает его высокую эффрективность и перспективность применения в качестве препарата выбора топической монотерапии микробной экземы.

Ключевые слова: микробная экзема, наружная терапия

Конфрликт интересов: авторы заявляют об отсутствии потенциального конфликта интересов, требующего раскрытия в данной статье.

Для цитирования: Тлиш М. М., Кузнецова Т. Г., Наатыж Ж. Ю, Псавок Ф. А. Микробная экзема: возможности коррекции на современном этапе. Вестник дерматологии и венерологии. 2018;94(4):60-67.

https://doi.org/10.25208/0042-4609-2018-94-4-60-67 


\title{
Wicrobial eczema: possibilities of correction at the present stage
}

\author{
Marina M. Tlish, Taisiya G. Kuznetsova*, Zhanna Yu. Naatyzh, Fatima A. Psavok
}

Kuban State Medical University of the Ministry of Health of the Russian Federation

Rashpilevskaya str., 179, Krasnodar, 350000, Russian Federation

Microbial eczema is a chronic recurrent dermatosis characterized by evolutionary polymorphism of the elements of the rash, sputum, itching, allergic reaction of the sensitized skin to the products of the decay of microorganisms and their toxins, developing against the background of a long-existing pyogenic focus in violation of the most important regulatory systems of the body.

Purpose: to study the biocenosis of the skin in patients with microbial eczema and to evaluate the clinical efficacy and safety of the cream "Tetraderm" in such patients.

Materials and methods. Patients with microbial eczema were observed, randomly selected into two groups. All patients studied biocenosis of the skin before and after treatment. Patients of the study group received topical therapy with the cream "Tetraderm". External therapy for patients of the comparison group was carried out with cream of mometasone furoate in combination with erythromycin and clotrimazole ointments. The effectiveness of the therapy was evaluated taking into account the clinical dynamics of the skin process, bacteriological data on the content of pustules and detachable erosion, calculation of the EASI and DIJ indices.

Results. A comparative analysis of the biocenosis of microbial eczema foci in patients of both groups at the end of therapy showed a higher severity of disbiotic changes in the comparison group. As a result of our study found that patients who used the cream "Tetraderm", there was a more rapid regression of dermatosis, almost complete suppression of pathogenic bacterial flora, a significant improvement in the quality of life. Conclusion. The biocenosis of the skin of patients with microbial eczema was characterized by a high degree of contamination of Staphylococcus aureus and Staphylococcus epidermidis, against the background of the average verification of Streptococcus spp., Candida spp. The combination of pronounced anti-inflammatory, antibacterial, antimicotic and regenerating effects of the cream "Tetraderm" causes its high efficiency and prospects of use as a drug of choice of topical monotherapy of microbial eczema.

Keywords: microbial eczema, topical therapy

Conflict of interest: the authors state that there is no potential conflict of interest requiring disclosure in this article.

For citation: Tlish M. M., Kuznetsova T. G., Naatyzh Zh. Yu., Psavok F. A. Microbial eczema: possibilities of correction at the present stage. Vestnik Dermatologii i Venerologii. 2018;94(4):60-67. https://doi.org/10.25208/0042-4609-201894-4-60-67 
Микробная экзема - хронический рецидивирующий дерматоз, характеризующийся эволюционным полиморфизмом элементов сыпи, мокнутием, зудом, аллергической реакцией сенсибилизированной кожи на продукты распада микроорганизмов и их токсины, развивающийся на фоне длительно существующего пиогенного очага при нарушении важнейших иммунных и эндокринных регуляторных систем организма [1].

Согласно современным представлениям пусковым, поддерживающим и отягчающим фрактором у больных экземой может являться микробная сенсибилизация [2].

В патогенезе микробной экземы играют важную роль $\beta$-гемолитический стрептококк группы В, представители рода стафрилококков - золотистый и эпидермальный стафрилококки. Микробная экзема может вызываться и неспецифическими возбудителями, такими как Proteus vulgaris, Neisseria meningitidis, Neisseria gonorrhoeae, Cl. perfringens, Cl. histolyticum, Cl. septicum, Pseudomonas aeroginosa. Возрастает количество дрожжеподобных грибов рода Candida, участвующих также в экзематозном процессе более чем в половине случаев [3]. При хронических дерматозах нередко происходит нарушение баланса микроорганизмов на поверхности кожи, обусловленное увеличением выделения воды через эпидермис, нарушением секреции сальных желез, нарушением кератинизации, сдвигом $\mathrm{pH}$ кожи из кислой в нейтральную сторону [4].

В настоящее время большинство авторов отводят ведущее место в патогенезе микробной экземы разнообразным иммунным нарушениям [5]. Патогенные микроорганизмы обладают достаточно выраженной антигенной активностью, что ведет к сенсибилизации организма и способствует перестройке иммунного ответа [6].

У больных микробной экземой регистрируется относительное увеличение содержания лимфоцитов, экспрессирующих на своей поверхности CD4+, CD25+, $\mathrm{CD}^{+} 5^{+}, \mathrm{CD}^{+}$, HLA-DR ${ }^{+}$маркеры, увеличение соотношения $\mathrm{CD}^{+} / \mathrm{CD}^{+}$, относительное уменьшение содержания клеток, экспрессирующих $\mathrm{CD}^{+}, \mathrm{CD}^{+} 6^{+}$маркеры и фагоцитарной активности лейкоцитов. Снижение уровня $\mathrm{CD}^{+}$, возможно, связано с их перераспределением в очаг воспаления в коже. Увеличение экспрессии $\mathrm{HLA} \mathrm{DR}^{+}$является адекватной реакцией Т-лимфоцитов на антигенную стимуляцию. Супрессия В-лимфоцитов приводит к более тяжелым поражениям организма антигеном. Угнетение гуморального иммунного ответа проявляется в снижении концентраций сывороточных $\operatorname{lgM}, \operatorname{lgG}$, комплемента, повышении концентраций сывороточного $\lg$ А и миелопероксидазы [7]. В связи с активным воспалительным процессом в коже наблюдается увеличение концентрации провоспалительных цитокинов: ИЛ-8 и ИЛ-1а, а уровень ИЛ-1 $\beta$ и ФНО-а, напротив, снижается [7].

Вышеописанное свидетельствует о том, что возможность внедрения инфекционных агентов зависит, прежде всего, от состояния иммунной системы [5]. При первичных или при вторичных иммунодесицитных состояниях в ответ на внедрение микробных или химических аллергенов развивается слабый иммунный ответ. Возникающая персистенция аллергенов приводит к еще большей дисфункции иммунной системы [8].

Устранение действия микробной, микотической диссеминации и нормализация биоценоза кожи при микробной экземе являются ключевым принципом лечения пациентов, препятствующим рецидивированию хронической экземы [1]. Поэтому важным аспектом терапии микробной экземы являются антибактериальные и антимикотические средства.

С учетом вышесказанного представляется патогенетически обоснованным применение топического комбинированного четырехкомпонентного препарата крема «Тетрадерм». Одним из компонентов лекарственного средства является антибиотик широкого спектра действия из группы аминогликозидов - гентамицина сульфат, активный в отношении ряда грамположительных (Staphylococcus aureus) и грамотрицательных (Pseudomonas aeruginosa, Aerobacte raerogenes, Klebsiella pneumonia, Proteus vulgaris, Escherichia coli и др.) бактерий. Второй компонент представлен противогрибковым препаратом синтетического производного имидазола эконазолом, который оказывает фунгицидное и антибактериальное действие в отношении дрожжеподобных грибов рода Candida, Corynebacterium minutissimum, Malassezia furfur и дерматофитов Microsporum, Trichophyton, Epidermophyton. Третьим компонентом является синтетический глюкокортикостероид - мометазона фуроат, обладающий выраженным антиэкссудативным, противозудным и противовоспалительным эффектами. В состав препарата также включен декспантенол - производное пантотеновой кислоты, который стимулирует регенерацию кожи, нормализует клеточный метаболизм, ускоряет митоз и увеличивает прочность коллагеновых волокон. Таким образом, препарат одновременно оказывает антибактериальное, фрунгицидное, противовоспалительное, противозудное и регенерирующее действие.

Целью настоящего исследования явилось изучение биоценоза кожи у больных микробной экземой и оценка клинической эффективности и безопасности применения крема «Тетрадерм» у таких пациентов.

\section{Материалы и методы}

Под наблюдением на кафедре дерматовенерологии Федерального государственного бюджетного образовательного учреждения высшего образования «Кубанский государственный медицинский университет» Минздрава России находились 60 пациентов (26 мужчин, 34 женщины) с микробной экземой средней степени тяжести. Продолжительность заболевания составляла от 2 месяцев до 1 года. У 37 (61,6 \%) больных кожный патологический процесс носил ограниченный, у 23 (38,4\%) пациентов распространенный характер.

Критерии включения в исследование:

- возраст старше 18 лет;

- больные с диагнозом «микробная экзема»;

- максимальная давность заболевания до одного года.

Критерии исключения:

- использование топических средств с антибактериальным, фунгицидным или фунгистатическим действием в течение 2 недель до начала исследования;

- применение в терапии системных глюкокортикостероидов, антибактериальных, противогрибковых препаратов в течение 2 недель до начала исследования;

- опухоли кожи;

- язвенные поражения кожи.

Все пациенты методом случайного отбора были разделены на 2 равнозначные группы: 1-я - исследу- 
емая группа и 2-я - группа сравнения. Для верификации микробных агентов у всех больных проводили бактериологическое исследование содержимого пустул и отделяемого эрозий. Пациенты обеих групп получали традиционную системную терапию: десенсибилизирующие средства, антигистаминные препараты, седативные и ферментные препараты. Больные исследуемой группы $(n=30)$ получали топическую терапию кремом «Тетрадерм» 2 раза в день на протяжении 14 дней. Наружная терапия пациентов группы сравнения $(n=30)$ проводилась кремом мометазона фруроата в сочетании с эритромициновой и клотримазоловой мазями 2 раза в день в течение 14 дней. Эффективность проводимой терапии оценивали на 7-й и 14-й день с учетом данных бактериологического исследования содержимого пустул и отделяемого эрозий, расчета индексов EASI (Eczema Area and Severity Index), ДИКЖ (Дерматологический Индекс Качества Жизни), клинической динамики экзематозного процесса.

Биоценоз очагов микробной экземы до начала лечения у пациентов группы исследования и группы сравнения характеризовался широким спектром видового состава: S. aureus, S. epidermidis, Streptococcus spp., Candida spp., которые высеивались как в виде монокультуры, так и в виде ассоциации 3-4 микроорганизмов. С учетом вышесказанного, представляется патогенетически обоснованным применение топического комбинированного препарата крема «Тетрадерм» в группе исследования, а в группе сравнения топического глюкокортикостероида в сочетании с препаратами, обладающими антибактериальным и антимикотическим эффектами. Топическим глюкокортикостероидом в обеих группах являлся мометазона фруроат. Антимикотический эфффект как в группе исследования, так и в группе сравнения осуществлялся противогрибковыми препаратами синтетического производного имидазола. В связи с высокой степенью обсемененности Staphylococcus aureus, Staphylococcus epidermidis на фоне средних показателей верификации Streptococcus spp. антибактериальная топическая терапия была выбрана препаратами широкого спектра действия в обеих группах. В группу сравнения производное пантотено- вой кислоты не было включено с целью сравнительной оценки быстроты наступления регенерирующего эффректа в процессе лечения у пациентов обеих групп.

\section{Результаты и обсуждение}

Биоценоз очагов микробной экземы до начала лечения у пациентов группы исследования характеризовался широким спектром видового состава. Доминирующим видом являлся S. aureus, выделяемый в 100,0 \% (30) случаев. У 70,0 \% (21) пациентов установлена колонизация кожных покровов S. epidermidis; Streptococcus spp., Candida spp. культурально верифицировались у $66,6 \%$ (20) и 43,3 \% (13) обследуемых соответственно.

В группе сравнения лидирующее положение также занимал S. aureus - 100,0 \% (30) больных. Бактериологический анализ пациентов данной группы выявил наличие высокой степени колонизации: S. epidermidis в 73,3 \% (22), Streptococcus spp. в 60,0 \% (18), Candida spp. в 36,6 \% (11) случаев (рис. 1).

Анализируя полученные данные пациентов обеих групп, можно резюмировать, что у 28,3 \% (17) больных микроорганизмы высеивались в виде монокультуры, у остальных 71,6 \% (43) - в виде ассоциации 3-4 микроорганизмов.

На 7-й день терапии (рис. 2А, 2Б, 2B, 2Г) у пациентов исследуемой группы в видовом составе биотопов отмечалось статистически значимое $(p<0,05)$ снижение доли S. aureus до 40,0\% (12), тогда как в группе сравнения он был идентифицирован в 70 \% (21) случаев. В аналогичный период только у 36,6 \% (11) больных первой группы был констатирован S. epidermidis, а во второй группе отмечены более высокие его показатели - 66,6 \% (20). Анализ верификации Streptococcus spp., Candida spp. у пациентов первой группы выявил значительное уменьшение $(p<0,05)$ их численности: до 20,0 (6) и 16,6 \% (5) соответственно. Во второй группе обсемененность Streptococcus spp. была получена у 46,6 \% (14), Candida spp. - у $30 \%$ (9) больных, т.е. практически не отличалась от исходной.

На 14-й день терапии (рис. 2А, 2Б, 2В, 2Г) установлено статистически достоверное $(p<0,05)$ снижение $S$. aureus как в первой, так и во второй группах -

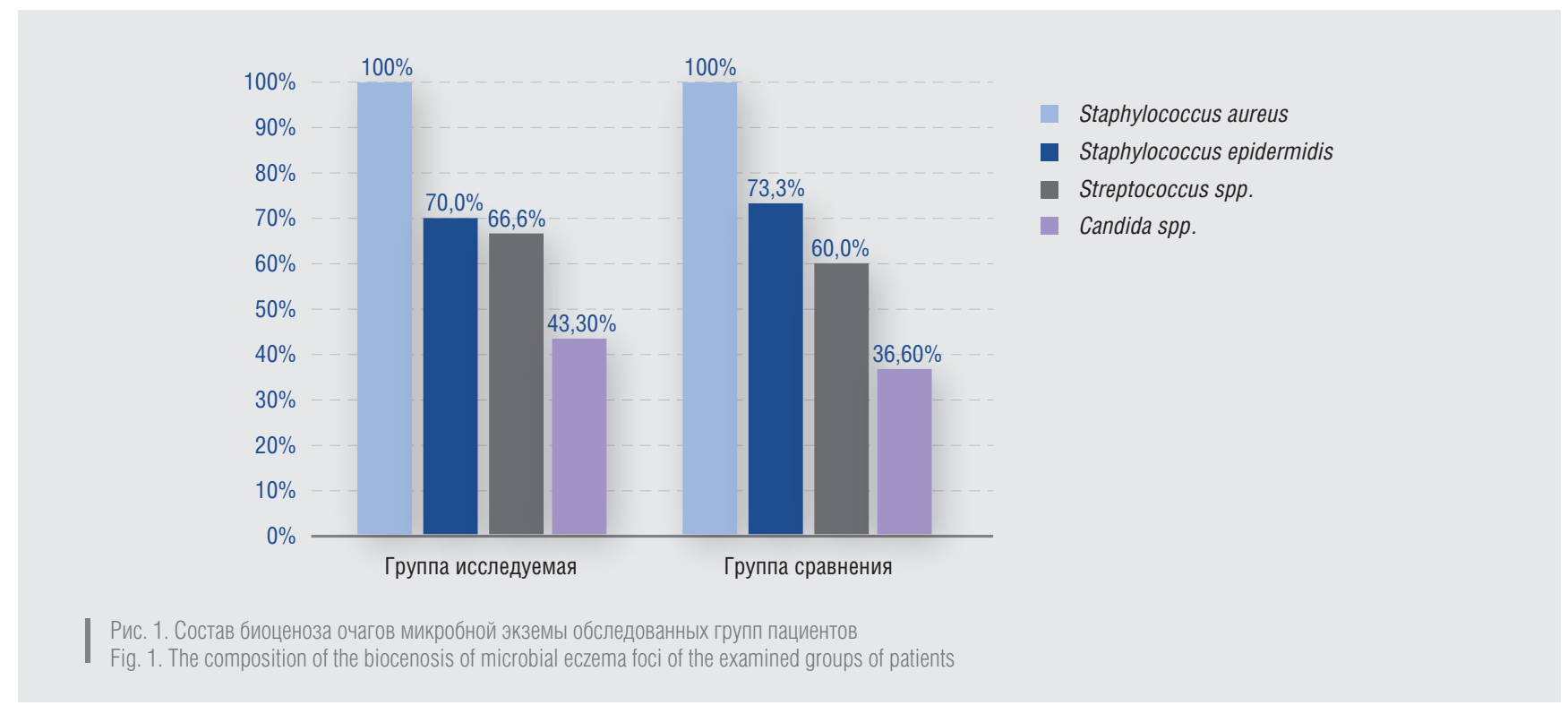


Рис. 2. Динамика верификации в очагах поражения у пациентов микробной экземой в процессе терапии (а — S. aureus; 6 - S. Epidermidis; в — Streptococcus spp., г - Candida spp.)

Fig. 2. Dynamics of verification in lesion foci in patients with microbial eczema during therapy. (a — S. aureus ; 6 — S. Epidermidis B — Streptococcus spp., $\Gamma$ — Candida spp.)



Рис. 2а. Динамика верификации S. аureus в очагах поражения у пациентов микробной экземой в процессе терапии

Fig. 2a. Dynamics of verification of $S$. aureus in lesion foci in patients with microbial eczema during therapy

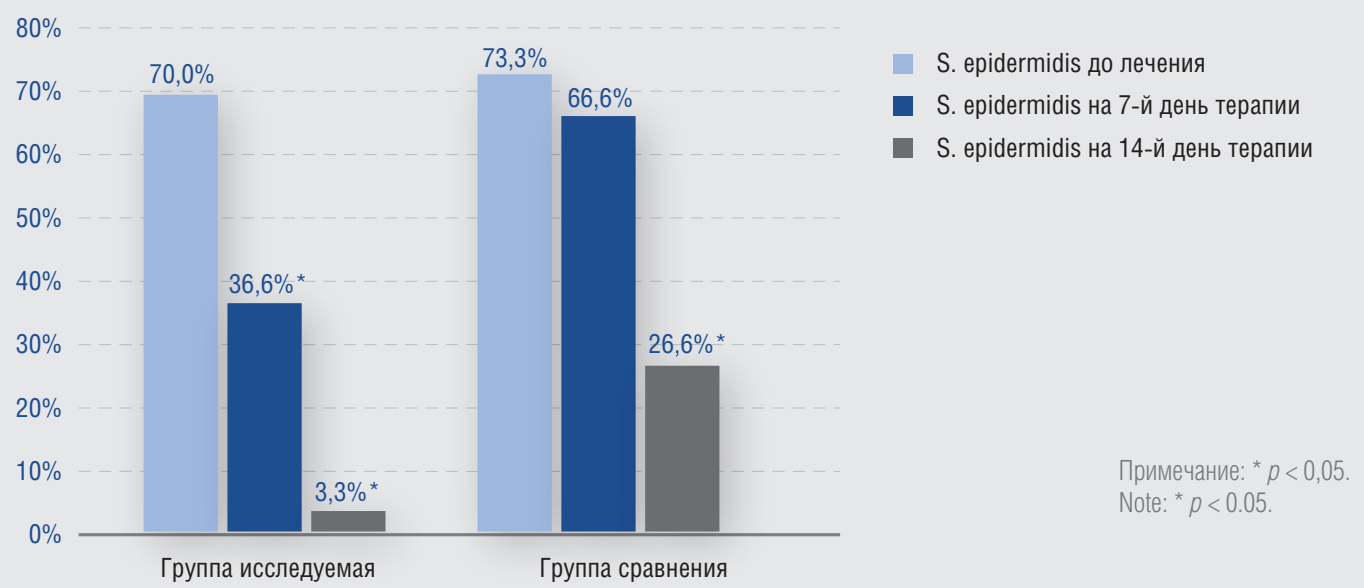

Рис. 2б. Динамика верификации S. Epidermidis в очагах поражения у пациентов микробной экземой в процессе терапии

Fig. 26. Dynamics of verification of $S$. Epidermidis in lesion foci in patients with microbial eczema during therapy

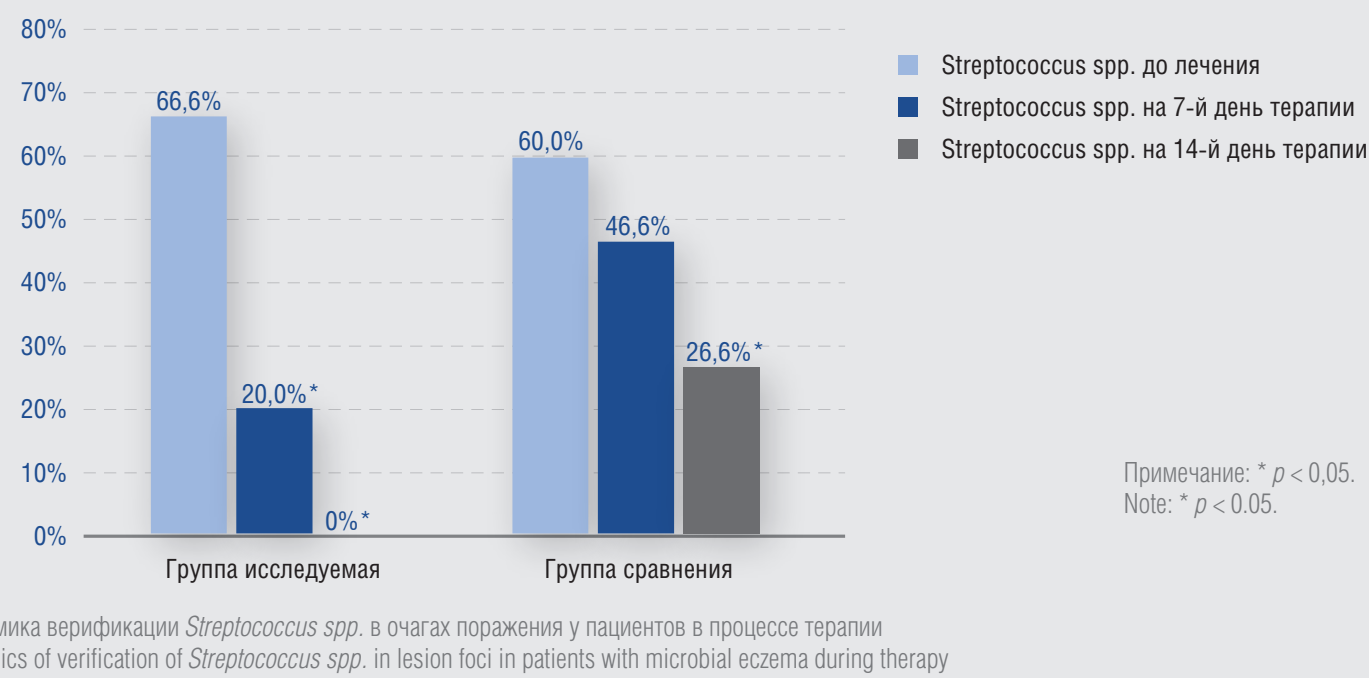




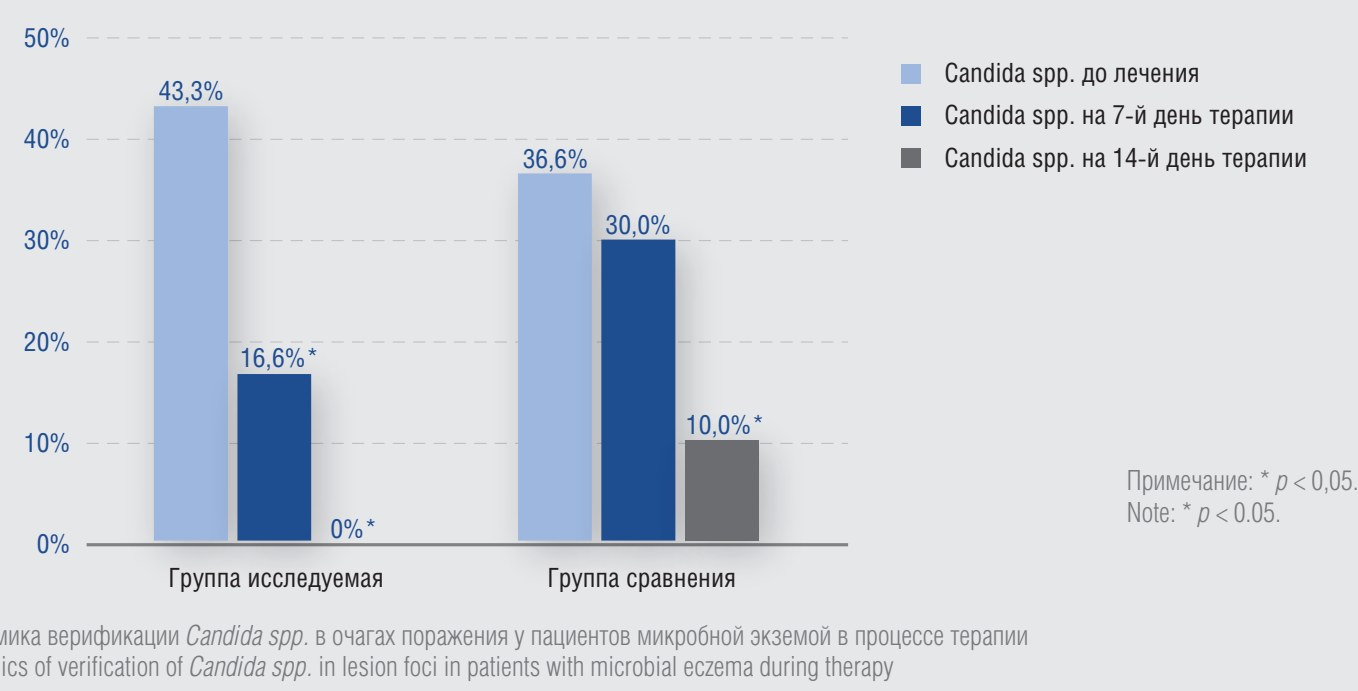

до 10,0 (3) и 33,3 \% (10) случаев соответственно. Необходимо заметить, что к моменту окончания исследования доля S. aureus была выше в 3,33 раза во второй группе. Показатели выявления Staphylococcus epidermidis у пациентов исследуемой группы были очень низкими - 3,3 \% (1), а в группе сравнения составили 26,6 \% (8) случаев, что в 8,06 раза выше, чем в первой группе. Streptococcus spp., Candida spp. в исследуемой группе не верифицировались, а в группе сравнения сохранялись у 26,6 (8) и 10,0\% (3) пациентов.

Сравнительный анализ биоценоза очагов микробной экземы у пациентов обеих групп к моменту окончания терапии показал более высокую выраженность дисбиотических изменений в группе сравнения.

Величины индекса EASI (рис. 3) до начала лечения у пациентов обеих групп (исследуемой и сравнения) были практически идентичны - 35,8 и 35,6 соответственно. На 7-е сутки в первой группе отмечалось более выраженное снижение значения индекса EASI - до 24,7 в сравнении со второй группой, где показатель понизился незначительно - до 31,6. Значимое снижение показателя мы наблюдали к 14-му дню терапии в обеих группах - до 10,2 и 22,3 соответственно
( $p<0,05)$, однако в первой группе значение индекса EASI снизилось в 3,50, а во второй только в 1,59 раза.

Исходное значение ДИКЖ (рис. 4) у пациентов первой группы составило 21,1, второй - 20,3. На 7-й день терапии у пациентов исследуемой группы зафиксировано падение значения индекса до 11,8, тогда как в группе сравнения он опустился только до 18,4. Статистически значимое снижение величины ДИКЖ до $7,1(p<0,05)$ зарегистрировано в первой группе к моменту окончания терапии, а у пациентов второй группы данный показатель был в 2,29 раза выше и соответствовал 16,3.

Анализ динамики кожного патологического процесса выявил более ранний регресс и отчетливое уменьшение площади поражения кожи и тяжести течения экзематозного процесса у пациентов, получавших терапию кремом «Тетрадерм», по сравнению с пациентами группы сравнения. Эфффективность препарата была зарегистрирована уже на 5-е сутки применения: активно регрессировали гиперемия, отечность, зуд, жжение.

В результате проведенного нами исследования установлено, что у пациентов, применявших крем

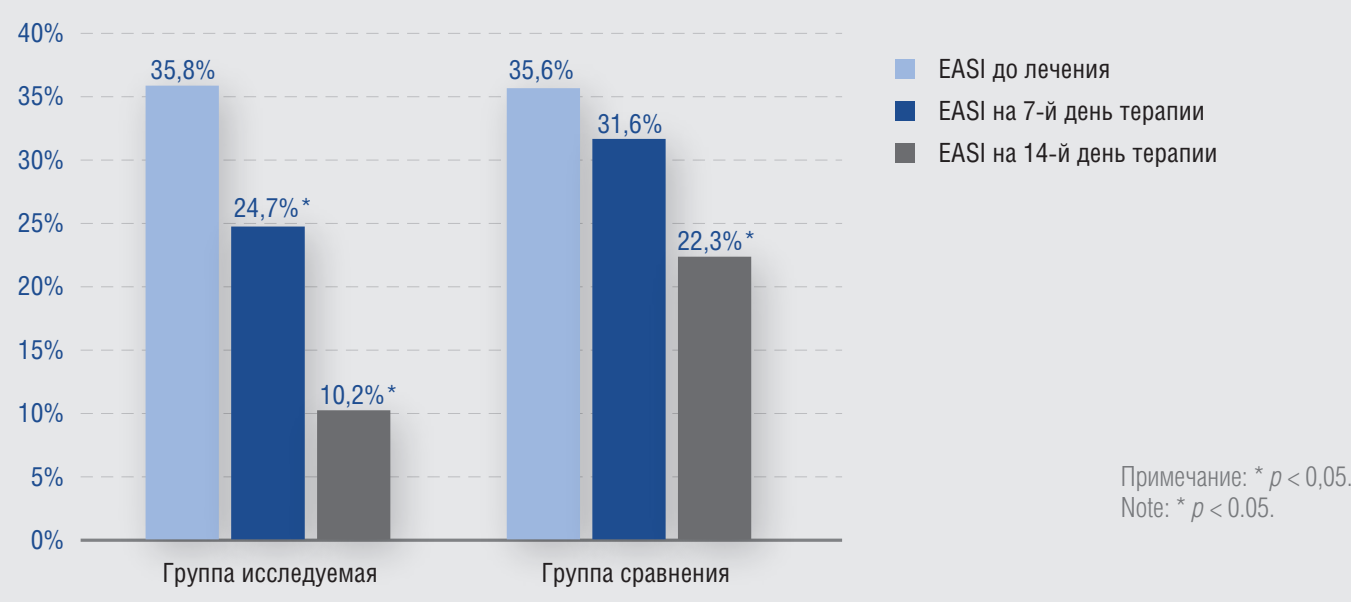

Рис. 3. Динамика индекса EASI у пациентов с микробной экземой в процессе терапии

Fig. 3. The dynamics of the EASI index in patients with microbial eczema during therapy 


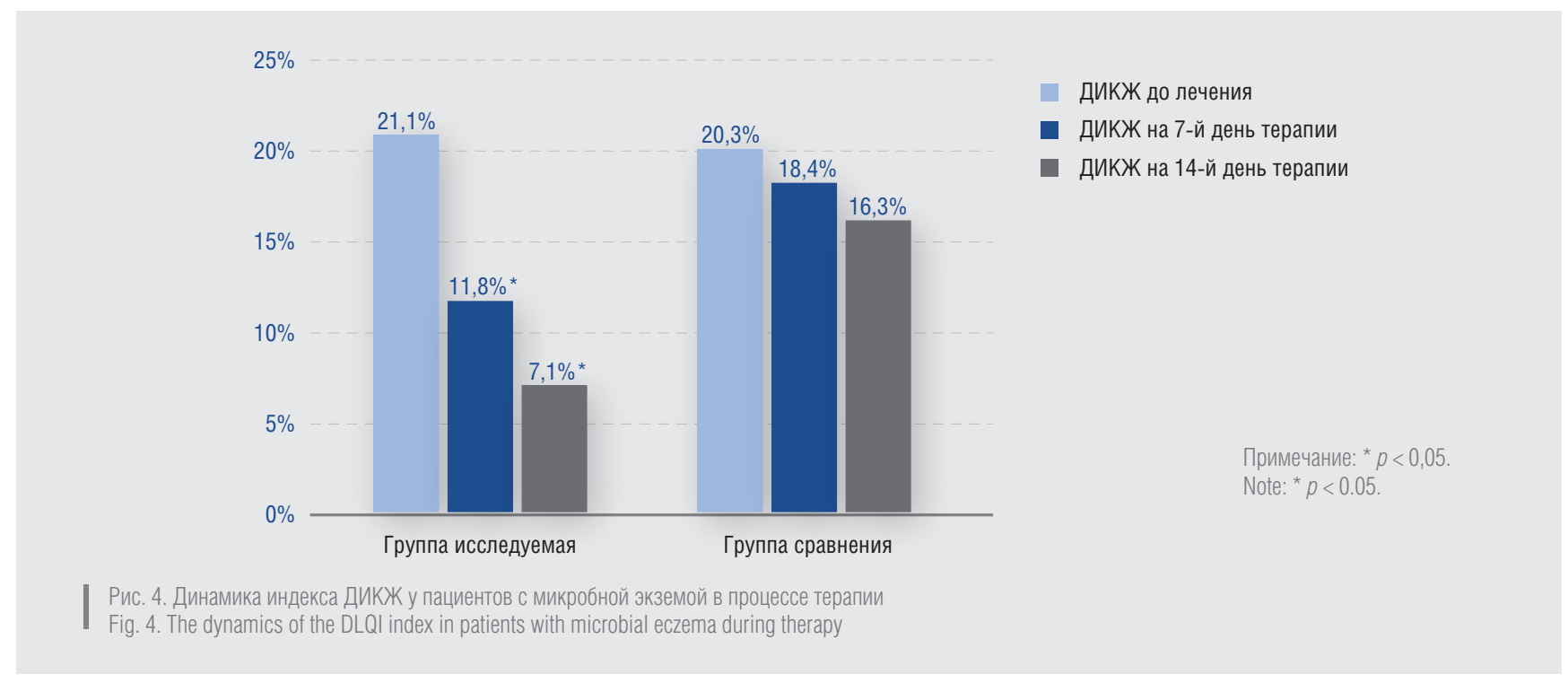

«Тетрадерм», на фроне устранения дисбиоза отмечался более быстрый регресс дерматоза, практически полное подавление патогенной бактериальной фрлоры и значительное улучшение качества жизни.

\section{Вывод}

Биоценоз кожи больных микробной экземой характеризовался высокой степенью обсемененности Staphy- lococcus aureus и Staphylococcus epidermidis на фроне средних показателей верификации Streptococcus spp., Candida spp. Комбинация выраженного противовоспалительного, антибактериального, антимикотического и регенерирующего эффректов крема «Тетрадерм» обуславливает его высокую эффективность и перспективность применения в качестве препарата выбора топической монотерапии микробной экземы.

\section{Литература/References}

1. Kubanova A. A. (ed.) Dermatovenerology (Clinical guidelines. Russian society of dermatologists and venereologists). M.: DEKS-Press, 2010: 428.

2. Haslund P., Bangsgaard N., Jarløv J. O. et al. Staphylococcus aureus and hand eczema severity. Br J Dermatol. 2009 Oct;161(4):772-777.

3. Bartlett A. Adult eczema. Nurs Stand. 2010 Jun 30 - Jul 6;24(43):51.

4. Nadarchenko R. M., Abdrahimova N. A. Imelbayeva E. A., Khismatullina Z. R. Improvement of diagnostic and treatment approaches to therapy numulyarnaya forms of microbial eczema. Russian Journal of Immunology. 2016;10(19):320-321.

5. Biagini Myers J. M., Khurana Hershey G. K. Eczemainearly life: genetics, the skin barrier, and lessons learned from birth cohort studies. J Pediatr. 2010 Nov;157(5):704-714.

6. Nikonova I. V, Orlov E. V., Konnov P. E. The state of biocenosis of the skin with microbial eczema. Practical Medicine. 2011;2:80-83.

7. Nadarchenko R. M., Abdrahimova N. A. Imelbayeva E. A., Khismatullina Z. R., Gareev E. M. The Role of correction of the level of interleukin$1 \beta$ in the treatment numulyarnaya microbial eczema. Russian Journal of Immunology. 2016;10(19):322-323.

8. Abdrakhimova N. A., Mustafina G. R., Khismatullina Z. R., Zakharchenko V. D. Immunological concept of microbial eczema development. Medical Bulletin of Bashkortostan. 2014;9(1):109-118. 


\section{Информация об авторах}

Марина Моссовна Тлиш - д.м.н., профессор, зав. кафедрой дерматовенерологии Кубанского государственного медицинского университета Министерства здравоохранения Российской Федерации

Таисия Георгиевна Кузнецова* - К.М.Н., ассистент кафедры дерматовенерологии Кубанского государственного медицинского университета Министерства здравоохранения Российской Федерации; e-mail: taya1504@mail.ru

Жанна Юрьевна Наатыж - к.м.Н., ассистент кафедры дерматовенерологии Кубанского государственного медицинского университета Министерства здравоохранения Российской Федерации

Фатима Александровна Псавок - к.м.Н., ассистент кафедры Кубанского государственного медицинского университета Министерства здравоохранения Российской Федерации

\section{Information about the authors}

Marina M. Tlish — Dr. Sci. (Med.), Prof., Departmental Head, Department of Dermatovenereology, Kuban State Medical University of the Ministry of Health of the Russian Federation

Taisiya G. Kuznetsova* - Cand. Sci. (Med.), Assistant, Department of Dermatovenereology, Kuban State Medical University of the Ministry of Health of the Russian Federation; e-mail: taya1504@mail.ru

Zhanna Yu. Naatyzh - Cand. Sci. (Med.), Assistant, Department of Dermatovenereology, Kuban State Medical University of the Ministry of Health of the Russian Federation

Fatima A. Psavok - Cand. Sci. (Med.), Assistant, Department of Dermatovenereology, Kuban State Medical University of the Ministry of Health of the Russian Federation 